\title{
MODELLING NATURAL MORTALITY OF TROPICAL PLANTATION SPECIES Acacia mangium Willd.
}

\author{
HARUNI KRISNAWATI* \\ Forest Research and Development Centre, Forestry and Environment Research Development and Innovation Agency (FORDA) \\ Bogor 16115, Indonesia
}

Received 06 April 2017 / Accepted 30 January 2018

\begin{abstract}
Natural mortality of trees is extremely variable due to the uncertainty and complexity of the functioning of forest ecosystems. The objective of this study was to develop a stand-level mortality model for Acacia mangium species by relating mortality to stand variables that affect the natural mortality process. The model was developed using data from 197 permanent sample plots measured periodically at 1-yr time intervals from 2-4 years until 8-11 years after planting in South Sumatra, Indonesia. The model consists of two complementary equations. The first equation is a logistic function predicting the probability of mortality incidence depending on stand density, site index and stand age. The second equation estimates the reduction in the number of surviving stems observed in a stand where natural mortality occurs. Nine equations were fitted using data from permanent sample plots where trees died over the time period and the best model was selected. Estimates from this second model were then adjusted by a factor equal to the probability of mortality applying three different approaches: probabilistic twostep, deterministic threshold and stochastic. All methods revealed no significant difference between the observed and the predicted number of surviving stems per ha. The probabilistic two-step approach, however, produced more consistent and the most accurate estimates. This method should provide reliable prediction when it is to be used in forest productivity prediction and management system for the species.
\end{abstract}

Keywords: logistic function, mangium, mortality model, stand density, survival

\section{INTRODUCTION}

Mortality of trees is a natural process that plays important roles in forest ecosystems and has a strong impact on stand production. This information needs to be accurately estimated as forest productivity may be sensitive to periodic lost due to mortality, especially over longer period of time with changing climate (Zhang et al. 2015; Ma et al. 2016). However, natural mortality of trees is extremely variable and difficult to predict due to the uncertainty and complexity of the functioning of forest ecosystems (Monserud \& Sterba 1999; Fridman \& Ståhl 2001; Ma et al. 2016). Natural mortality of trees can be distinguished into two types: regular (non-catastrophic) and irregular (catastrophic) mortality. Regular mortalities can be defined as being due to suppression and

*Corresponding author: h.krisnawati@yahoo.co.id competition between trees for light, water and soil nutrients within a stand; while irregular mortality is caused by random disturbances or hazards such as fire, wind, landslide, pest and disease outbreaks (Vanclay 1994).

Generally, only regular mortality is considered when modelling survival or stand density and data from sample plots showing excessive mortality caused by catastrophic events are usually excluded from analyses (Amateis et al. 1997; Woollons 1998; DiéguezAranda et al. 2005). Regular mortality is more predictable than irregular mortality (Murty \& McMurtrie 2000), particularly at tree and stand levels but not necessarily at a landscape level (Alenius et al. 2003).

In an attempt to simplify an approach to such a complex phenomenon, mortality has been commonly modelled within individual tree or stand level, either as regular or irregular mortality. Models for predicting mortality or 
survival have been developed, particularly for some species growing in temperate forests such as Pinus taeda (Avila \& Burkhart 1992; Amateis et al. 1997; Lee \& Coble 2002), Pinus elliottii (Pienaar \& Shiver 1981; Bailey et al. 1985; Pienaar et al. 1990), Pinus radiata (Woollons 1998; González et al. 2004), Pinus sylvestris (DiéguezAranda et al. 2005), and Picea glauca (Evert 1981; Yang et al. 2003). In contrast, a very few mortality models have been published for tropical plantation species (Forss et al. 1996).

In Indonesia, natural mortality of trees in a stand has usually been predicted simply as a mean annual mortality rate. Accurate prediction of natural mortality at the stand level is important, particularly for tropical species such as Acacia mangium which has been planted largely to meet the demand for wood industries. This prediction should be included in the management system to maintain the forest productivity and mitigate the risk of potential loss due to mortality. Forss et al. (1996) developed a model for predicting survival of $A$. mangium species in South Kalimantan but it was based on data from only a small number of semi-permanent sample plots and covered young ages only. To provide reliable information for estimating forest productivity, a more accurate mortality model for various stand conditions and covers the longer time period needs to be developed.

This study aimed to develop a stand level mortality model for Acacia mangium, one of the most commonly planted tropical species in Indonesia (FAO 2002; Krisnawati et al. 2011; Krisnawati 2016) by relating mortality to stand variables that affect the natural mortality process. Different causes of mortality are not separated so the model combines regular mortality due to suppression or normal competition and irregular mortality from random disturbances.

\section{MATERIALS AND METHODS}

\section{Data Description}

Data for this study were based on measurement of 197 permanent sample plots established subjectively in $A$. mangium unthinned stands in South Sumatra, Indonesia. The study area has a lowland humid environment which is well suited for growing $A$. mangium. The plots are good representative for the study site representing the range of ages, stand densities and site qualities. All plots were 0.1 ha in size but their initial planting spacing varied. Almost all of the plots were re-measured at 1-year time intervals until 8-11 years of age. For each measurement, the following stand variables were calculated: stand density in terms of total number of stems per ha $(N)$, basal area per ha $(B)$, dominant height $(H)$, site index $(S)$ which follows a function of Krisnawati et al. (2009), and relative spacing index (RS) which is a function of the number of stems per ha and the mean dominant height (Husch et al. 2003). Summary statistics including mean, minimum (min), maximum $(\max )$ and standard deviation (SD) of these variables for the initial measurement of each period are presented (Table 1). The data were split randomly into two sets: $75 \%$ was used for model fitting and 25\% was used for model validation.

Table1 Summary of the main stand variables at the initial measurement of each period

\begin{tabular}{|c|c|c|c|c|c|c|c|c|}
\hline \multirow{2}{*}{ Stand variable } & \multicolumn{4}{|c|}{ Fitting data } & \multicolumn{4}{|c|}{ Validation data } \\
\hline & Mean & Min & Max & SD & Mean & Min & Max & SD \\
\hline Stand age (yrs) & 5.5 & 2.0 & 10.0 & 1.8 & 5.2 & 2.0 & 9.0 & 1.7 \\
\hline Dominant height (m) & 16.2 & 3.6 & 27.0 & 4.7 & 15.1 & 5.0 & 25.5 & 4.3 \\
\hline Site index $(\mathrm{m})$ & 17.8 & 8.4 & 23.9 & 2.7 & 17.1 & 11.7 & 22.8 & 2.3 \\
\hline Stand density (stems ha-1) & 966 & 390 & 2020 & 282 & 882 & 390 & 1930 & 290 \\
\hline Basal area $\left(\mathrm{m}^{2} \mathrm{ha}^{-1}\right)$ & 15.7 & 0.7 & 31.6 & 7.2 & 15.2 & 1.8 & 30.4 & 7.4 \\
\hline Relative spacing index & 19.0 & 11.1 & 69.5 & 7.5 & 25.8 & 11.8 & 76.2 & 11.1 \\
\hline
\end{tabular}


Proportion of dead stems in the plots was recorded during the re-measurement times. Natural mortality (at least one stem dying in a plot) occurred in $75.1 \%$ of the measurement periods of the fitting plots and $72.8 \%$ for the validation plots. For a few plots having measurement periods of 2 years, data were transformed into 1-year using linear interpolation. The overall annual mortality rates of all available plots ranged from 0.4 to $38.3 \%$ with a mean value of $5.7 \%$. High mortality occurred mainly in plots with very high stand densities, consistent with the result of the extreme inter-tree competition.

\section{Modelling Mortality}

A stand level difference equation was used as the base model for modelling mortality to predict stand density at a specified projection age:

$$
N_{2}=f\left(N_{1}, A_{2}, A_{1}\right)
$$

where $N_{2}$ is number of surviving stems per ha at age $A_{2}, N_{1}$ is number of surviving stems per ha at age $A_{1}$, and the difference between $A_{1}$ and $A_{2}$ is the projection interval.

This type of equation has been commonly used for projecting stand density because of its desirable properties, including consistency, pathinvariance and the asymptotic limit of stand density approaching zero when the projected stand age $\left(A_{2}\right)$ becomes very large (Clutter et al. 1983). However, Woollons (1998) argued that a conflict exists between the mathematical characteristics of the difference equations for stand density projection and the data used to estimate their parameters. As the most common data used for estimating mortality models are from repeated measurements of permanent plots, in some plots mortality may not occur, even over periods of several years (Monserud \& Sterba 1999; Eid \& Tuhus 2001; Fridman \& Ståhl 2001). In this study, for example, no mortality occurred between two successive measurements in $25.5 \%$ of the available time intervals in the full data set. If data from all plots (i.e. those in which mortality had not occurred as well as those in which it had occurred in that time interval) were included in model development, certain problems related to the binomial nature of mortality and fitting of the above model are likely to appear (Woollons 1998; Eid \& Øyen 2003). On the other hand, if only data from plots where mortality had occurred were used in model development, mortality would be overestimated.

To overcome these problems, this study followed Woollons (1998) suggestion by applying a two-step modelling approach similar to the decision theory or a probabilistic two-step approach (Hamilton \& Brickell 1983) for estimating the defective volume of timber in a stand. In the first step, a model is fitted using all sample plots to predict the probability of a plot experiencing any mortality. In the second step, a model to estimate the number of surviving stems (stand density) is fitted only to the sample plots in which some mortality has occurred. Finally, the estimates derived from the second step are adjusted by a factor equal to the probability of mortality estimated in the first step to produce the overall prediction of the number of surviving stems per ha.

\section{Predicting Probability of Mortality Incidence}

The first step in modelling mortality was estimating the probability of mortality incidence in a plot (at least one stem dying in a plot) over a 1 -year period. Incidence of mortality is considered as a discrete event with only two possible values, i.e. 0 (absence of mortality) or 1 (presence of mortality). The logistic regression model (Hosmer et al. 2013; Chutinantakul et al. 2014) was applied to predict the probability of mortality incidence:

$$
\pi(x)=\frac{e^{b^{\prime} X}}{1+e^{b^{\prime} X}}+\varepsilon \ldots \ldots \ldots \ldots \ldots \ldots \ldots \ldots \ldots \ldots \ldots \ldots \ldots
$$

where $\pi(x)$ is the probability of mortality incidence in a plot over a 1-year period (and the probability of no mortality is $1-\pi(x)$ ), $x$ is the vector of explanatory variables which characterise the stand conditions at the initial measurement, $b$ ' is the vector of parameters to be estimated, and $\varepsilon$ is a random error.

Due to the binary nature of dependent variable, a logit transformation is needed to estimate the parameters: 


$$
\hat{\pi}(x)=\frac{1}{1+\exp \left(-\left(\hat{b}_{0}+\hat{b}_{1} X_{1}+\ldots+\hat{b}_{n} X_{n}\right)\right)}
$$

The explanatory variables considered for inclusion in the logistic regression model (Eq. 3) are stand attributes that potentially influence the likelihood of a stem death: (1) stand density, (2) site productivity, and (3) stand vitality. The most commonly used stand density measure is the number of stems per ha $(N)$ (Burgman et al. 1994; Wang \& Hamilton 2003; González et al. 2004), stand basal area (B) (Vanclay 1991b; Yang et al. 2003; Diéguez-Aranda et al. 2005), and relative spacing index (RS) (González et al. 2004; Zhao et al. 2006). Site productivity, usually characterised by dominant height $(H)$ or site index $(S)$, has also been found to influence mortality (Woollons 1998; Eid \& Tuhus 2001; Yao et al. 2001; Bravo-Oviedo et al. 2006). Age $(A)$ is considered as a reasonable measure of vitality, particularly in unthinned stands, also influences the likelihood of a stem mortality (González et al. 2004; Diéguez-Aranda et al. 2005; Zhao et al. 2006). All these variables and some combinations of them were included for analysis in this study.
The generalized estimating equation (GEE) method (Stokes et al. 2012; Hosmer et al. 2013) was employed to handle correlated data in the logistic regression analysis due to serial correlation between measurements in the same plots, which has not been addressed in some previous studies (Eid \& Øyen 2003; Wang \& Hamilton 2003; González et al. 2004; DiéguezAranda et al. 2005; Zhao et al. 2006). This method is an extension of generalised linear model (GLM), suitable for binomially distributed data with repeated measurements.

\section{Estimating Stand Density}

The second step in modelling mortality was to develop a model to estimate stand density for a specified projection age using data from only sample plots where mortality has occurred in that time interval. Several algebraic difference equations derived from four differential equations were tested in this study as candidate models for predicting stand density (Table 2). Comparison of the model estimates was based on graphical and numerical analyses of residuals, following the criteria as used by Krisnawati et al. (2009) for modelling dominant height and site index for A. mangium.

Table 2 Difference-equation forms of stand mortality models tested in this study

\begin{tabular}{|c|c|c|}
\hline Model & Expression & References \\
\hline \multicolumn{3}{|c|}{ Mortality rate is constant, independent of age: } \\
\hline M1 & $N_{2}=N_{1} \exp \left(c_{0}\left(A_{2}-A_{1}\right)\right)$ & Clutter et al. (1983) \\
\hline \multicolumn{3}{|c|}{ Mortality rate is proportional to a power function of age: } \\
\hline & $N_{2}=\left(N_{1}^{-0.5}+c_{0}\left(\left(A_{2} / 100\right)^{2}-\left(A_{1} / 100\right)^{2}\right)\right)^{-2}$ & Woollons (1998) \\
\hline M3 & $N_{2}=\left(N_{1}^{-0.5}+c_{0}\left(\left(A_{2} / 100\right)^{b_{2}}-\left(A_{1} / 100\right)^{b_{2}}\right)\right)^{-2}$ & Modification of M2 \\
\hline M4 & $N_{2}=\left(N_{1}^{-0.5}+c_{1} S\left(\left(A_{2} / 100\right)^{b_{2}}-\left(A_{1} / 100\right)^{b_{2}}\right)\right)^{-2}$ & M3 with site index \\
\hline \multicolumn{3}{|c|}{ Mortality rate is proportional to a hyperbolic function of age: } \\
\hline M5 & $N_{2}=N_{1}\left(A_{2} / A_{1}\right)^{b_{2}} \exp \left(c_{0}\left(A_{2}-A_{1}\right)\right)$ & Diéguez-Aranda et al. (2005) \\
\hline M6 & $N_{2}=N_{1}\left(A_{2} / A_{1}\right)^{b_{2}} \exp \left(c_{1} S\left(A_{2}-A_{1}\right)\right)$ & M5 with site index \\
\hline $\mathrm{M} 7$ & $N_{2}=N_{1}\left(A_{2} / A_{1}\right)^{b_{2}} \exp \left(c_{0}+c_{1} S\left(A_{2}-A_{1}\right)\right)$ & Bailey et al. (1985) \\
\hline \multicolumn{3}{|c|}{ Mortality rate is proportional to an exponential function of age: } \\
\hline M8 & $N_{2}=N_{1} \exp \left(c_{0}\left(b_{2}^{A_{2}}-b_{2}^{A_{1}}\right)\right)$ & Laar \& Akça (1997) \\
\hline M9 & $N_{2}=N_{1} \exp \left(c_{1} S\left(b_{2}^{A_{2}}-b_{2}^{A_{1}}\right)\right)$ & M8 with site index \\
\hline
\end{tabular}

Note: $A_{1}$ is initial age (yr), $A_{2}$ is re-measurement age (yr), $N_{1}$ is number of surviving stems per ha at age $A_{1}, N_{2}$ is number of surviving stems per ha at age $A_{2}$, and $b_{1}, b_{2}$ and $c_{0}$ are model parameters to be estimated 


\section{Adjusting the Predicted Stand Density}

Final prediction of stand density involves combining the models from the two preceding steps and adjusting the predicted survival. The predictions can be calculated by deterministic and stochastic approaches (Weber et al. 1986; Monserud \& Sterba 1999). The most common deterministic approach is based on decision theory and called a "probabilistic two-step approach" (Hamilton \& Brickell 1983; Woollons 1998), where the predicted number of surviving stems per ha $\left(N_{\text {adj } 2}\right)$ is determined by:

$$
N_{a d j 2}=N_{1}-\hat{\pi}(x)\left(N_{1}-\hat{N}_{2}\right) \text {. }
$$

where $\hat{\pi}(\mathrm{x})$ is the probability of mortality incidence over the period estimated by the logistic model (Eq. 3), $N_{1}$ is the number of surviving stems per ha at the initial age $A_{1}$, and $\hat{N}_{2}$ is the number of surviving stems per ha at the prediction age $A_{2}$ predicted by the selected mortality model (Table 2).

Another deterministic approach is to use a threshold value between 0 and 1 . If $\hat{\pi}(\mathrm{x})$ exceeds the threshold value, then natural mortality occurs and the number of surviving stems per ha at age $A_{2}$ is estimated by the algebraic difference form of the mortality model; otherwise natural mortality does not occur and the number of surviving stems per ha at age $A_{2}$ equals the initial number of surviving stems per ha. The most logical choice of a threshold is the average observed mortality rate (Monserud \& Sterba 1999) which in this study it is equal to 0.745 .

In the stochastic approach, the predicted probability of mortality incidence is compared with a random number between 0 and 1 . If the random number is less than $\hat{\pi}(\mathrm{x})$, natural mortality occurs and the number of surviving stems per ha at age $A_{2}$ is estimated using the algebraic difference form of the mortality model; if not, then the prediction is for no natural mortality.

\section{Model Evaluation}

Performance of the whole mortality models based on the probabilistic two-step approach
(Eq. 4), the deterministic threshold and the stochastic approaches were evaluated using the validation data set, and scatter plots of observed and predicted numbers of surviving stems per ha were produced for each. A simple linear regression was fitted for each approach and the coefficients of determination were used to compare the observed and the predicted number of surviving stems per ha. The observed $(N)$ and the predicted $(\hat{N})$ values were related following the linear model: $\hat{N}=b_{0}+b_{1} N$. If the mortality model estimated the number of surviving stems per ha correctly, the intercept $\left(b_{0}\right)$ should not be significantly different from zero and the slope $\left(b_{1}\right)$ should not be significantly different from one.

\section{RESULTS AND DISCUSSION}

\section{Model for Predicting Probability of Mortality Incidence}

The probability of mortality incidence in the stand was well explained by a logistic regression model. The model is appropriate for dealing with the binary nature of mortality data. In the logistic model for predicting the probability of a stand experiencing any mortality in a 1-year period, the best set of explanatory variables was stand density, site index and stand age (Table 3). Other variables (basal area, dominant height) were also tested. However, these two variables were less significant for predicting the probability of mortality incidence (based on the probability level of 0.05 ) allowing these to be removed from the model. Variability of these variables, however, may have been incorporated in the main explanatory variables.

The selected model for predicting probability of mortality incidence in a stand is:

$$
\hat{\pi}(x)=\frac{1}{1+\exp \left(-\left(-2.9+0.001 N_{1}+0.121 S+0.18 A_{1}\right)\right)} . .
$$

where $A_{1}$ is stand age at the initial measurement (yr), $N_{1}$ is number of stems per ha at age $A_{1}$, and $S$ is site index $(\mathrm{m})$. 
Table 3 Parameter estimates, standard errors and related fit statistics of the selected model for predicting the probability of mortality incidence

\begin{tabular}{lcccc}
\hline \multicolumn{1}{c}{ Variable } & Estimate & $\boldsymbol{S E}$ & Wald $\chi^{2}$ statistics & $\boldsymbol{p}$-value \\
\hline Intercept & -2.9 & 0.58 & -5.07 & 0.000 \\
Stand density $\left(N_{1}\right)$ & 0.0010 & 0.00037 & 2.85 & 0.004 \\
Site index $(S)$ & 0.121 & 0.0290 & 4.15 & 0.000 \\
Stand age $\left(A_{1}\right)$ & 0.18 & 0.055 & 3.29 & 0.001 \\
\hline
\end{tabular}

The positive coefficient for the number of stems per ha (stand density) indicates that for stands of a given age and site index the predicted probability of mortality incidence increases with increasing stand density due to more intense inter-tree competition. The degree of competition may influence the survival likelihood of each individual tree. In stands with high density, trees compete for limited physical space and resources such as light, water and soil nutrients (Peet \& Christensen 1987). Some trees may fail the competition and die. The influence of this variable was also shown in other stand or tree mortality models (Woollons 1998; Yao et al. 2001).

The probability of mortality incidence in a stand also tends to increase with increasing site index, which is consistent with many previous studies (Eid \& Tuhus 2001; Yao et al. 2001; Eid \& Øyen 2003; Diéguez-Aranda et al. 2005). Yao et al. (2001) and Yang et al. (2003) explained that faster tree growth on better sites may lead to more severe competition and increased probability of mortality, especially for small trees. The faster growth in stand of higher site productivity also triggers competition-induced mortality at earlier ages (Oliver \& Larson 1996). However, Vanclay (1994) criticized that highquality sites should support higher densities; therefore, stand mortality should be lower for given age and stand density. Woollons (1998) also found higher mortality on lower production sites. This could be attributed to the lower availability of water and certain nutrients, which might be the case on poorer sites (Jutras et al. 2003). For $A$. mangium, water availability may not be a problem as this species normally demands full light for good development and gets stunted when grown in shade (Lim et al. 2002). It may also be possible that the higher mortality on higher site quality could be partly an effect of higher local competition, coupled with a strong tendency of $A$. mangium to produce multiple leaders resulting in stand densities high enough to cause self-thinning in some plots. This cannot properly be accounted for by robust stand-level mortality models. Incorporating spatial competition measures may help in understanding and modelling this phenomenon but it is beyond the scope of this study as spatial data are not typically available in forest inventory.

Probability of mortality incidence also increases with stand age. This seems to be explainable because the data were from unthinned stands, which often exhibit increasing mortality, particularly after 5 years from planting (Arisman et al. 2005). This result complies with the dynamic process of the competition and natural mortality of even-aged stands (Clutter et al. 1983; Gadow \& Hui 1999).

The mean predicted probabilities of mortality incidence (at least one stem dying in a plot) with respect to number of stems per ha, site index and stand age in $A$. mangium stands generally coincide with the mean observed mortality within each class, despite the occasional discrepancies (Fig. 1). The differences between mean values of the predicted and the observed probability of mortality mainly occurred in the smallest and the largest classes of each stand variable, where there were small numbers of observations. Irregular or stochastic conditions that may apply during the measurement periods may have also contributed to the lower or higher predicted mortality incidence than observed. For all observations of all plots, the mean predicted probability of mortality incidence was $71.9 \%$, while the actual incidence was $72.8 \%$. 

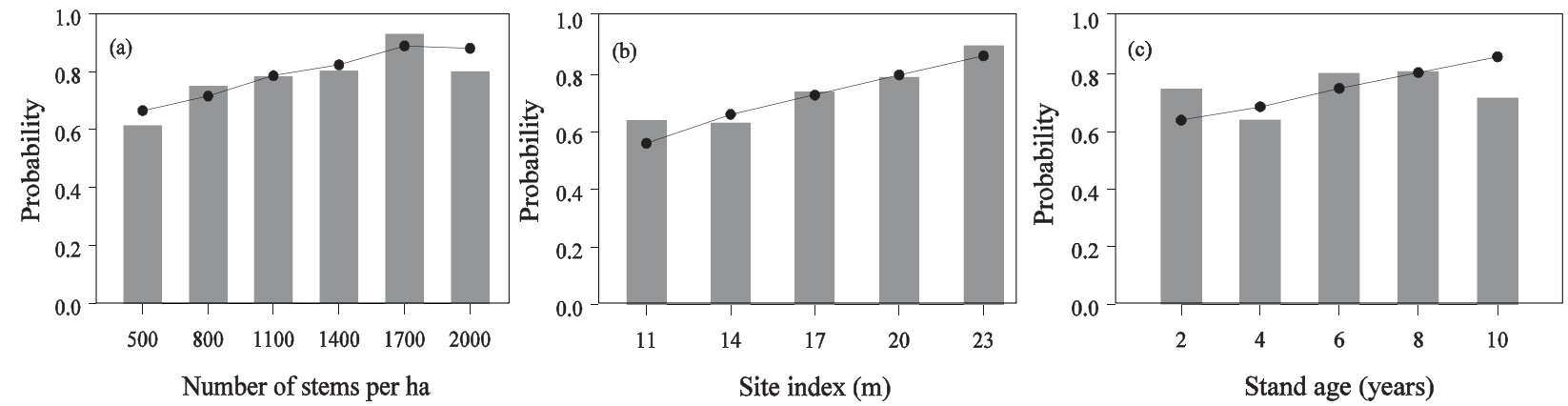

Figure 1 Predicted (line) and observed (bar) probability of mortality incidence computed for three stand variables: number of stems per ha (a), site index (b) and stand age (c)

\section{Models for Predicting Stand Density}

The final parameter estimates for the nine fitted models as well as their standard errors $(S E), t$-statistics, $p$-values for significance testing, model root mean squared error (RMSE), and adjusted coefficient of determination $\left(R_{\text {adi }}^{2}\right)$ are presented in Table 4. All models produced similar fits with values of $R M S E$ and $R_{\text {adj }}^{2}$ almost identical. All parameter estimates were found to be highly significant $(\phi<0.01)$, except for parameter $c_{0}$ in Model M8 and parameter $c_{1}$ in Model M9. The $R_{\text {adj }}^{2}$ for all models were generally high (> 94\%), compared with other studies for similar models producing $R_{\text {adj }}^{2}$ for only 16-50\% (Fridman \& Ståhl 2001; Eid \& Øyen 2003; Pothier \& Mailly 2006). The RMSEs were relatively high at about 60 stems per ha $(6.5 \%)$ over a period of $1-2$ years. This can be explained by the occurrence of irregular mortality during the measurement periods that may also contribute to the model's errors. However, this is not unusual for mortality models emphasizing the fact that mortality is a complex and fairly unpredictable process for which there are many interrelated causes (Waring 1987).

Table 4 Final parameter estimates, standard errors and related fit statistics of the fitted models for predicting stand density

\begin{tabular}{|c|c|c|c|c|c|c|c|}
\hline Model & Parameter & Estimate & $S E$ & $t$ & $p$-value & $R M S E$ & $\boldsymbol{R}^{2}{ }_{a d j}$ \\
\hline \multicolumn{8}{|c|}{ Mortality rate is constant, independent of age: } \\
\hline M1 & $c_{0}$ & -0.0539 & 0.00292 & -18.45 & 0.000 & 61.010 & 0.946 \\
\hline \multicolumn{8}{|c|}{ Mortality rate is proportional to a power function of age: } \\
\hline M2 & $c_{0}$ & 0.65 & 0.036 & 18.36 & 0.000 & 60.221 & 0.947 \\
\hline \multirow[t]{2}{*}{ M3 } & $b_{2}$ & 1.31 & 0.182 & 7.19 & 0.000 & 59.896 & 0.948 \\
\hline & $c_{0}$ & 0.15 & 0.056 & 2.69 & 0.007 & & \\
\hline \multirow[t]{2}{*}{ M4 } & $b_{2}$ & 1.29 & 0.184 & 7.03 & 0.000 & 59.401 & 0.949 \\
\hline & $c_{1}$ & 0.0078 & 0.00292 & 2.68 & 0.004 & & \\
\hline \multicolumn{8}{|c|}{ Mortality rate is proportional to a hyperbolic function of age: } \\
\hline \multirow[t]{2}{*}{ M5 } & $b_{1}$ & 0.13 & 0.041 & 3.18 & 0.002 & 60.508 & 0.946 \\
\hline & $c_{0}$ & -0.077 & 0.0079 & -9.78 & 0.000 & & \\
\hline \multirow[t]{2}{*}{ M6 } & $b_{2}$ & 0.09 & 0.037 & 2.52 & 0.009 & 60.321 & 0.947 \\
\hline & $c_{1}$ & -0.0038 & 0.00038 & -9.97 & 0.000 & & \\
\hline \multirow[t]{3}{*}{ M7 } & $b_{2}$ & 0.15 & 0.040 & 3.79 & 0.000 & 58.748 & 0.949 \\
\hline & $c_{0}$ & -0.043 & 0.0082 & -5.27 & 0.000 & & \\
\hline & $c_{1}$ & -0.003 & 0.0043 & -6.21 & 0.000 & & \\
\hline \multicolumn{8}{|c|}{ Mortality rate is proportional to an exponential function of age: } \\
\hline \multirow[t]{2}{*}{ M8 } & $b_{2}$ & 1.064 & 0.0275 & 38.65 & 0.000 & 60.710 & 0.946 \\
\hline & $c_{0}$ & -0.6 & 0.35 & -1.70 & 0.090 & & \\
\hline \multirow[t]{2}{*}{ M9 } & $b_{2}$ & 1.057 & 0.0276 & 38.32 & 0.000 & 60.388 & 0.947 \\
\hline & $c_{1}$ & -0.037 & 0.0236 & -1.56 & 0.119 & & \\
\hline
\end{tabular}


Among the models that did not include site index as explanatory variable (Models M1, M2, M3, M5 and M8), Model M3, which assumes mortality rate is a power function of age performed slightly better than the others. This model is similar to Model M2 which was recommended by Woollons (1998) but his model included only one parameter. Model M1 proposed by Clutter et al. (1983) in which mortality rate is a constant proportion for all ages, site indices and stand densities does not appear to be suitable to this study. Its validation performance was inferior to all the others.

The inclusion of site index as an explanatory variable slightly improved the fits in all models as shown by Models M4, M6, M7 and M9. Model M7 proposed by Bailey et al. (1985) generally performed better than Models M4, M6 and M9. Although Model M7 provided good fit, when it was used for projecting number of stems from age 1 to age 2 years, it predicted an increase in the number of stems per ha, which was clearly illogical. This model should only be used for projecting survival from starting ages of 2 years or later. A similar problem occurs for Models M5 and M6, which also assume mortality rate is proportional to a hyperbolic function of age. Due to this limitation, the models that assume mortality rate is proportional to a hyperbolic function of age were rejected.

Models that consider the relative rate of change in the number of stems is proportional to an exponential function of age (Models M8 and M9) performed worst in terms of overall bias. One of the parameter estimates of each of these models was also not significant $(p>0.05)$. Although these types of models have been shown to be more accurate than others for Pinus radiata stands (González et al. 2004), they were less appropriate for $A$. mangium in this study.

In general, the models that consider the relative rate of change in the number of stems is proportional to a power function of age (Models M2, M3 and M4) seemed to be most suitable. These models behaved logically and fitted the data well. Similar results were reported by Diéguez-Aranda et al. (2005) for mortality model of Pinus sylvestris. Within this group, however, Model M4, which includes site index, was the best. Therefore, this model was selected for estimating the number of surviving stems per ha for $A$. mangium stands in this study. The final model (fitted from plots where mortality has occurred from the entire data set) is:

$$
\hat{N}_{2}=\left(N_{1}^{-0.5}+0.011 S\left(\left(A_{2} / 100\right)^{147}-\left(A_{1} / 100\right)^{1.47}\right)\right)^{-2}
$$

\section{Performance of the Selected Mortality Model}

Scatter plots of the observed and predicted values of the number of surviving stems per ha were produced for the three different approaches and a simple linear model was fitted for each (Fig. 2). In general, the three different approaches produced no aberrant results and the coefficients of determination were very similar $(0.975$ - 0.980). The test also revealed that the predicted number of surviving stems per ha of the three approaches was not significantly different from the observed number of surviving stems per ha $(p>0.30)$. All approaches should provide satisfactory predictions of the number of surviving stems per ha.
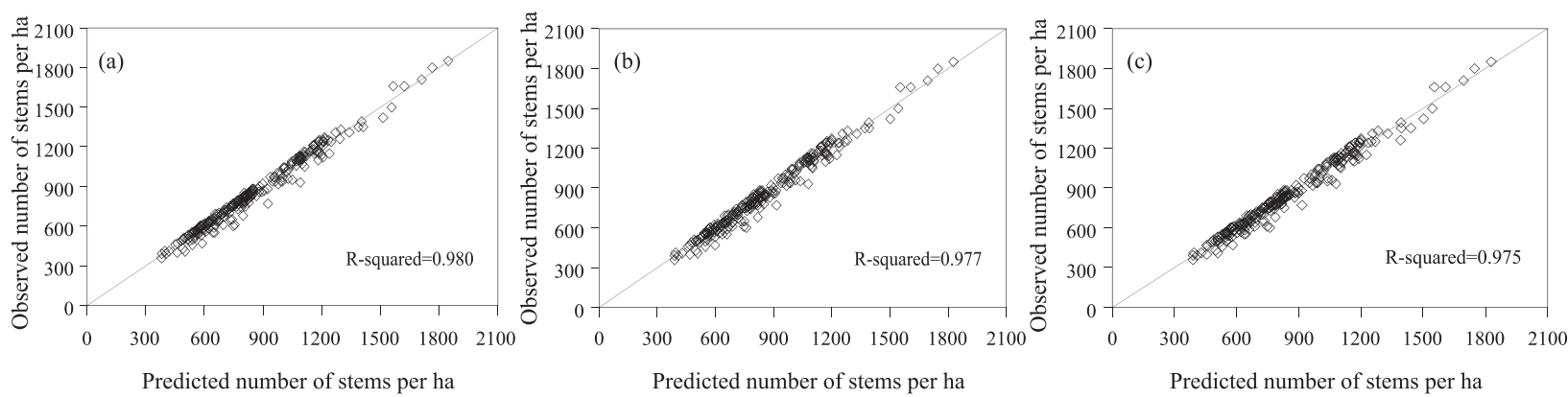

Figure 2 Scatter plots of observed and predicted number of surviving stems per ha using three different approaches: probabilistic two-step approach (a), deterministic threshold approach (b) and stochastic approach (c) 
The overall biases at the projection ages were generally small, and were not significantly different from zero. All methods predicted the number of surviving stems per ha reasonably well. Some discrepancies between the observed and the predicted number of surviving stems per ha at the projection ages were found for the highest density class. Prediction problems in the highest density class were not unexpected since few sample plots were available at densities higher than 1500 stems per ha. This is probably of little practical concern because stand density in operational $A$. mangium stands typically does not exceed this number.

The stand mortality models developed in this study can be used for predicting stand density through either deterministic or stochastic approach. Deterministic prediction based on the probabilistic two-step approach assumes that the incidence of mortality over the plots or stands will be affected equally according to the stand conditions. The deterministic use of the model in this way will smooth values of mortality trend for the plots or stands. However, with a reasonably large number of plots, the prediction of mortality will still be unbiased at the stand level or even at the forest level (Eid \& Øyen 2003). The threshold deterministic approach would avoid this "smoothing" values but it always produces the same estimate of stand mortality for a fixed threshold value (DiéguezAranda et al. 2005).

In real situations, mortality occurrence in the plots having the same growing conditions may not be the same due to the stochastic nature of tree mortality. In order to mimic the real situation more closely, the model may be used stochastically, despite it is having been developed for deterministic use. The probability of mortality incidence for a particular plot may be predicted from Eq. 6, and a random number distributed uniformly between 0 and 1 is used to determine whether or not the mortality occurred in the plot. The stochastic approach is, however, an alternative that allows different estimates for the same stand depending on the random number generated. The use of a random number may be a reasonable approach to deal with the fact that mortality is a stochastic phenomenon. This assumption may be more useful when the mortality model is used for large-scale management simulation, taking into account the stochastic nature of tree death (Woollons 1998).

Another alternative is to fit a model for predicting stand density as what has been applied in the second step but including all plots with and without mortality incidence. The use of this one-step modelling approach fitted to all data may be a good alternative when natural mortality is frequent, as may occur in unthinned dense stands. However, this approach may create a problem when no actual mortality is observed in many plots (Woollons 1998; Eid \& Øyen 2003). This approach was also tested in this study (results not shown), but some departure from normality and presence of large bias in prediction were indicated, which was consistent with the result of Woollons's study.

Weber et al. (1986) and Vanclay (1991a) compared the deterministic and stochastic approaches in predicting mortality and could not find significant difference in their predictions. However, Belcher et al. (1982) noted that a stochastic approach typically predicts high mortality during some years and very little mortality in others. Such patterns may be more representative of actual events over short time periods, but they may inflate the variance of predictions over long projection periods (Pothier \& Mailly 2006). Consequently, the deterministic prediction based on the probabilistic two-step approach was preferred to a stochastic approach for the application in this study. This approach has also been shown to be most accurate among the three approaches tested and thus should provide reliable prediction when it is to be used in forest productivity prediction and management system.

\section{CONCLUSION}

From the three different methods proposed for projecting the number of surviving stems per ha (i.e. probabilistic two-step, deterministic threshold and stochastic approaches), all methods provided similar results and reliable predictions. No important biases between the observed and the predicted number of surviving stems per ha were found. For inclusion in the forest productivity prediction system, however, the probabilistic two-step approach produces consistent and the most accurate estimates. 


\section{ACKNOWLEDGEMENTS}

The author thanks to the management and field inventory team of PT Musi Hutan Persada for providing access to permanent sample plot data for this study. Thanks also to reviewers who have provided invaluable comments on the earlier draft of this manuscript.

\section{REFERENCES}

Alenius V, Hökkä H, Salminen H, Jutras S. 2003. Evaluating estimation methods for logistic regression in modelling individual-tree mortality. In: Amaro A, Reed D, Soares P, editors. Modelling Forest Systems. Wallingford (UK): CAB International. p. 225-36.

Amateis RL, Burkhart HE, Liu J. 1997. Modeling survival in juvenile and mature loblolly pine plantations. For Ecol Manage 90(1):51-8.

Arisman H, Kurinobu S, Hardiyanto EB. 2005. A simple step-wise procedure for predicting stand development of Acacia mangium plantations based on the maximum size-density line in South Sumatra, Indonesia. J For Res 10(4):313-8.

Avila OB, Burkhart HE. 1992. Modeling survival of loblolly pine trees in thinned and unthinned plantations. Can J For Res 22(12):1878-82.

Bailey RL, Borders BE, Ware KD, Jones EP. 1985. A compatible model for slash pine plantation survival to density, age, site index, and type and intensity of thinning. For Sci 31(1):180-9.

Belcher DW, Holdaway MR, Brand GJ. 1982. A description of STEMS - the stand and tree evaluation and modelling system. USDA For Serv GTR-NC 79 .

Bravo-Oviedo A, Sterba H, Río MD, Bravo F. 2006. Competition-induced mortality for Mediterranean Pinus pinaster Ait. and P. sylvestris L. For Ecol Manage 222(1-3):88-98.

Burgman MA, Incoll W, Ades PK, Ferguson I, Fletcher T, Wohlers A. 1994. Mortality models for mountain and alpine ash. For Ecol Manage 67(1-3):319-27.

Chutinantakul A, Mayeng M, Tongkumchum P. 2014. Estimation of mortality with missing data using logistic regression. Songklanakarin J Sci Technol 36(2):249-54.

Clutter JL, Fortson JC, Pienaar LV, Brister GH, Bailey RL. 1983. Timber management: A quantitative approach. New York (US): Wiley.

Diéguez-Aranda U, Castedo-Dorado F, Álvarez-González JG, Rodríguez-Soalleiro R. 2005. Modelling mortality of Scots pine (Pinus sylvestris L.) plantations in the northwest of Spain. Eur J For Res 124(2):143-53.

Eid T, Øyen B-H. 2003. Models for prediction of mortality in even-aged forest. Scand J For Res 18(1):64-77.

Eid T, Tuhus E. 2001. Models for individual tree mortality in Norway. For Ecol Manage 154(1-2):69-84.

Evert F. 1981. A model for regular mortality in unthinned white spruce plantations. For Chron 2:77-9.

Food and Agriculture Organization (FAO). 2002. Tropical forest plantation areas data set by D. Pandey. Forest Plantations Working Paper 18. Rome (IT): FAO.

Forss E, Gadow KV, Saborowski J. 1996. Growth models for unthinned Acacia mangium plantations in South Kalimantan, Indonesia. J Trop For Sci 8(4):449-62.

Fridman J, Ståhl G. 2001. A three-step approach for modelling tree mortality in Swedish forests. Scand J For Res 16(5):455-66.

Gadow KV, Hui G. 1999. Modelling forest development. Dordrecht (NL): Kluwer Academic Publishers.

González JGA, Dorado FC, González ADR, Sánchez CAL, Gadow KV. 2004. A two-step mortality model for even-aged stands of Pinus radiata D.Don in Galicia (Northwestern Spain). Ann For Sci 61(5):439-48.

Hamilton DA, Brickell JE. 1983. Modeling methods for a two-stage system with continuous responses. Can J For Res 13(6):1117-21.

Hosmer DW, Lemeshow S, Sturdivant RX. 2013. Applied logistic regression, $3^{\text {rd }}$ edition. New York (US): Wiley.

Husch B, Beers TW, Kershaw JA. 2003. Forest mensuration. New Jersey (US): John Wiley \& Sons.

Jutras S, Hökkä H, Alenius V, Salminen H. 2003. Modelling mortality of individual trees in drained peatland sites in Finland. Silva Fenn 37(2):235-51.

Krisnawati H. 2016. A compatible estimation model of stem volume and taper for Acacia mangium Willd. plantations. Indon J For Res 3(1):49-64.

Krisnawati H, Wang Y, Ades PK, Wild I. 2009. Dominant height and site index models for Acacia mangium Willd. plantations. J For Res 6(2):148-65.

Krisnawati H, Kallio M, Kanninen M. 2011. Acacia mangium Willd.: Ecology, silviculture and productivity. Bogor (ID): CIFOR.

Laar A, Akça A. 1997. Forest mensuration. Göttingen (DE): Cuvillier Verlag.

Lee Y-J, Coble DW. 2002. A survival model for unthinned loblolly pine plantations that incorporates nonplanted tree competition, site quality, and incidence of fusiform rust. Bioresour Technol 85(3):301-8. 
Lim SC, Gan KS, Choo KT. 2002. The characteristics, properties and uses of plantation timbers rubberwood and Acacia mangium. Kuala Lumpur (MY): Timber Technology Centre, FRIM. p. 1-11.

Ma L, Lian J, Lin G, Cao H, Huang Z, Guan D. 2016. Forest dynamics and its driving forces of subtropical forest in South China. Sci Rep 6:22561. doi: $10.1038 / \operatorname{srep} 22561$

Monserud RA, Sterba H. 1999. Modeling individual tree mortality for Austrian forest species. For Ecol Manage 113(2-3):109-23.

Murty D, McMurtrie RE. 2000. The decline of forest productivity as stands age: A model-based method for analysing causes for the decline. Ecol Model 134(2-3):185-205.

Oliver CD, Larson BC. 1996. Forest stand dynamics. New York (US): Wiley.

Peet RK, Christensen NL. 1987. Competition and tree death. BioSci 37(8):586-95.

Pienaar LV, Page HH, Rheney JW. 1990. Yield prediction for mechanically site-prepared slash pine plantations. South J Appl For 14(3):104-9.

Pienaar LV, Shiver BD. 1981. Survival functions for siteprepared slash pine plantations in the flatwoods of Georgia and northern Florida. South J Appl For $5(2): 59-62$.

Pothier D, Mailly D. 2006. Stand-level prediction of balsam fir mortality in relation to spruce budworm defoliation. Can J For Res 36(7):1631-40.

Stokes ME, Davis CS, Koch GG. 2012. Categorical data analysis using SAS, $3^{\text {rd }}$ edition. Cary, NC (US): SAS Institute Inc.

Vanclay JK. 1991a. Compatible deterministic and stochastic predictions by probabilistic modeling of individual trees. For Sci 37(6):1656-63.
Vanclay JK. 1991b. Mortality functions for north Queensland rain forests. J Trop For Sci 4(1):15-36.

Vanclay JK. 1994. Modelling forest growth and yield: Applications to mixed tropical forests. Wallingford (UK): CAB International.

Wang Y, Hamilton F. 2003. Projecting stand attributes of regrowth ash eucalypts sampled in forest inventory. Aus For 66(2):75-86.

Waring RH. 1987. Characteristics of trees predisposed to die. BioSci 37:569-74.

Weber L, Ek AR, Droessler TD. 1986. Comparison of stochastic and deterministic mortality estimation in an individual tree based stand growth model. Can J For Res 16(5):1139-41.

Woollons RC. 1998. Even-aged stand mortality estimation through a two-step regression process. For Ecol Manage 105(1-3):189-95.

Yang Y, Titus SJ, Huang S. 2003. Modeling individual tree mortality for white spruce in Alberta. Ecol Model 163(3):209-22.

Yao X, Titus SJ, MacDonald SE. 2001. A generalized logistic model of individual tree mortality for aspen, white spruce, and lodgepole pine in Alberta mixedwood forests. Can J For Res 31(2):283-91.

Zhang J, Huang S, He F. 2015. Half-century evidence from western Canada shows forest dynamics are primarily driven by competition followed by climate. In: Franklin J, editor. PNAS. Available from:

www.pnas.org/cgi/doi/10.1073/pnas.1420844112

Zhao D, Borders BE, Wang M. 2006. Survival model for fusiform rust infected loblolly pine plantations with and without mid-rotation understorey vegetation control. For Ecol Manage 235(1-3):2329. 